\title{
Study on Risk factors, presentation and management of stroke in a tertiary care hospital
}

\author{
Sapkota S1, Chhetri H², Sharma RP ${ }^{3}$ \\ Universal College of Medical Science Teaching Hospital
}

1Department of Pharmacy, JF institute, Little Angels, Lalitpur, Nepal

2Department of Pharmacy, Kathmandu University, Dhulikhel, Nepal

${ }^{3}$ Department of Medicine, UCMS, Bhairawa, Nepal

\begin{abstract}
Background and Objectives: Many studies in recent years have focused attention on identification of risk factors associated with stroke. However, most of these studies have been conducted in the developed countries. Only few studies have been conducted in Nepal. So the present study has been undertaken with the aim of determining the risk factors and management pattern of stroke and makes the people aware of those factors.
\end{abstract}

Material and Methods: It is a descriptive prospective study conducted with 50 consecutive patients who presented in medicine and emergency department at Universal College of Medical Science, Bhairahawa, Nepal from December 2009 to July 2010. Data were collected using a standard questionnaire and encounter form after receiving a verbal consent from the patient. The collected data were coded, tabulated and analyzed using SPSS version- 16.

Results: The present study showed that $56 \%$ of stroke patients were male. Hemorrhagic stroke $(60 \%)$ was more than the ischemic stroke $(40 \%)$.The age was common non modifiable risk factor. The common-modifiable risk factors were hypertension (86\%), alcohol consumption (74\%) and smoking (56\%). Calcium channel blocker (44.18\%) and combination of it with Diuretic (18.60\%) and ACE inhibitors (20.93\%) were the commonly prescribed drugs for lowering blood pressure. Prescribed drugs therapy and lifestyle modification improved the health condition of patients (80\%). The non compliance to the drugs was due to multiple dosages (51.52\%), side effects $(18.18 \%)$ and forgetfulness $(18.18 \%)$.

Conclusion: Finding of this study will be helpful for the practitioners as well as researcher in the future. Practitioners can make people aware on the risk factors and preventive measures of the stroke. Researchers will be helped by knowing the commonest risk factors of stroke and its management pattern.

Key words: Stroke, Blood Pressure, Calcium channel blocker, life style modification

INRODUCTION

Disease of cerebral blood vessels are third most common cause of death in the developed world (after cancer and ischemic heart disease) and are responsible for a large proportion of physical disability, becoming 
more frequent with increasing age [1]. They cause approximately 2000,000 deaths in the United States each year [2]. For the past few decades, stroke has been a principle cause of death in the People's Republic of China, Japan and other Eastern Asian countries. The burden of stroke in this region is predicted to increase, both in absolute terms and as a proportion of total disease burden [3]. Albeit no population-based studies conducted in Nepal shows that, adoption of western lifestyle and an aging population places the Nepalese community at the increased risk of stroke [4].

Many studies in recent years have focused attention on identification of risk factors associated with stroke. However, most of these studies have been conducted in the developed countries. Only few studies have been conducted in Nepal. So the present study has been undertaken with the aim of determining the risk factors and management pattern of stroke and makes the people aware of those factors. The information obtained could be implemented for the prophylactic measures which will help in minimizing the incidence of this disease in future.

\section{MATERIALS AND METHODS}

This research is a descriptive prospective study conducted at Universal College of Medical Science, Bhairahawa from December 2009 to July 2010. A total number of 50 consecutive patients who presented in medicine and emergency department of UCMS Teaching hospital Bhairahawa, Nepal were enrolled into the study. The information was gathered by using a standard questionnaire and encounter form after receiving a verbal consent from the patient. Patient demographic data, lifestyle of the patient, patient family history, socioeconomic of the patient was included in the questionnaire. All the patient either male or female, young or adult who were diagnosed as stroke through CT scan was included in the study. The collected data were coded, tabulated and analyzed using SPSS version16.

\section{RESULTS}

The mean age for patients presenting with stroke was $64 \pm 11.8$ years. The mean age of stroke in male was $66 \pm 11.58$ years and for female $62 \pm 11.95$ years. The distribution of patients in different age groups as per their gender is shown in the figure 1 below.

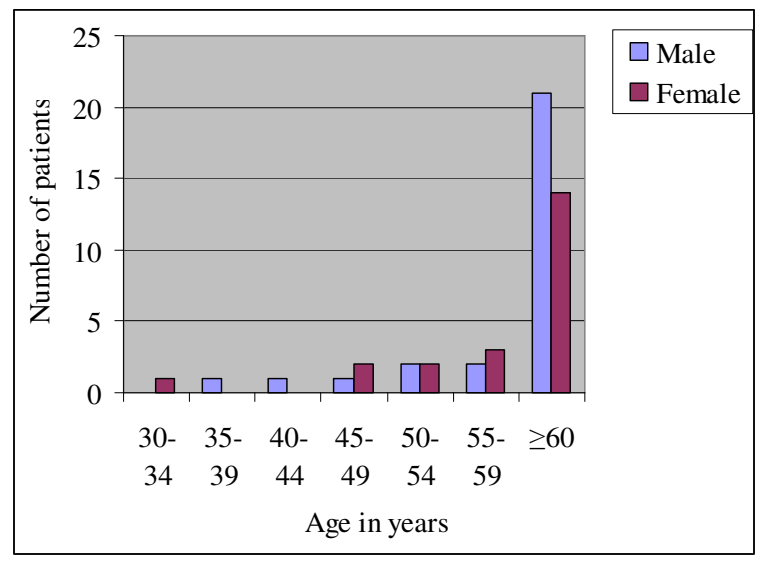

Figure 1: Stroke - Age and gender distribution of patients

Table 2 shows the status of hypertension among the stroke patients of the study. The study showed that $86 \%$ of stroke patients were hypertensive.

Table 1: Past medical history: Hypertension

\begin{tabular}{|c|c|c|}
\hline Hypertension & Number & $\begin{array}{c}\text { Percentage } \\
\text { (\%) }\end{array}$ \\
\hline Yes & 19 & 38.0 \\
\hline No & 7 & 14.0 \\
\hline $\begin{array}{c}\text { Yes } \\
\text { but not known before }\end{array}$ & 24 & 48.0 \\
\hline Total & 50 & 100.0 \\
\hline
\end{tabular}


The study showed that $74 \%$ of patients diagnosed of stroke were alcoholic and 28 (56\%) smokers. The details of alcohol consumption and smoking habits are presented in figures 2 to 4 .

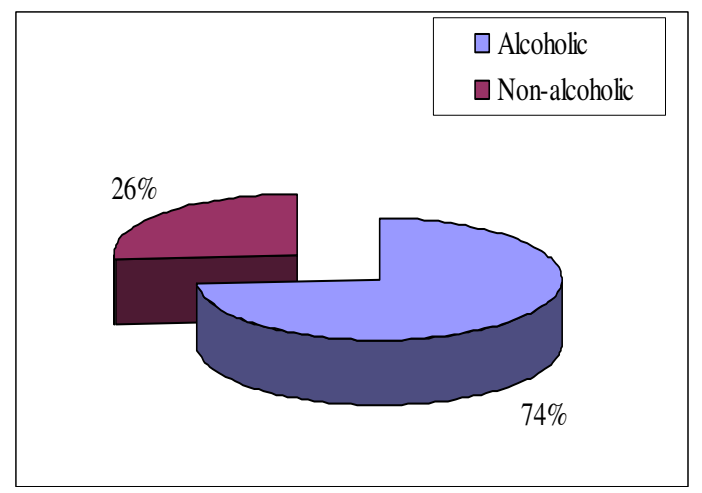

Figure 2: Percentage of patients taking alcohol

Patients consuming alcohol were again classified into heavy and mild alcoholic.

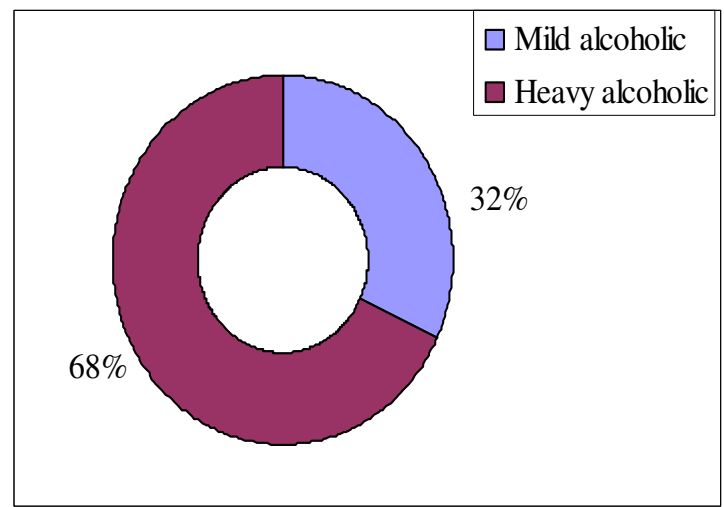

Figure 3: Percentage of patients taking level of consumption of alcohol/day

Those patients who consume alcohol more than 60gram/ day or more than 10 years were classified as heavy alcoholic, while those who consume less than 60 gram/ day were classified as mild alcoholic and those who consume less than 12 gram /day were not considered as alcoholic [5]. In the study it was found that heavy alcoholic were more susceptible than mild alcoholic towards stroke $(67.56 \% \%$ vs. $32.43 \%)$. The study showed that $28(56 \%)$ of patients diagnosed of stroke were smokers, which was the third commonest modifiable risk factors in the population studied.

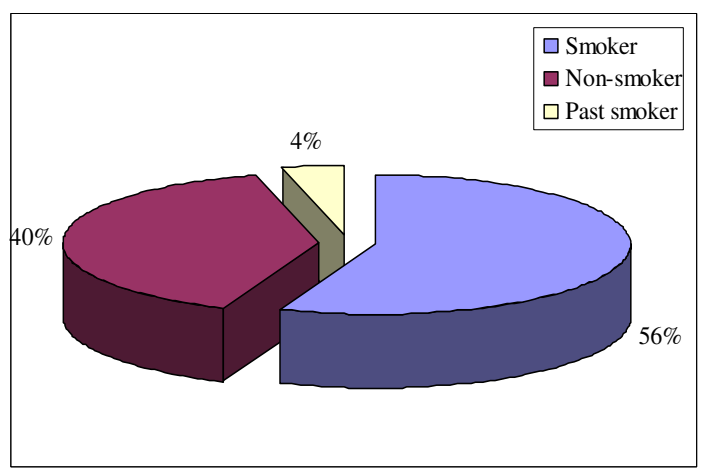

Figure 4: Smoking habit of the patient

The other modifiable risk factors of stroke with their prevalence besides hypertension, consumption of alcohol and smoking, are given below in the table 2 .

Table 2: Stroke - Other Modifiable Risk Factors

\begin{tabular}{cc}
\hline Risk factors & Prevalence \\
\hline Hyperlipidaemia & $18(36 \%)$ \\
Lifestyle factors & $8(16 \%)$ \\
Mental Stress & $7(14 \%)$ \\
Diabetes Mellitus & $5(10 \%)$ \\
Cardiac Disease & $4 \quad(8 \%)$ \\
Drug Abuse & $1(2 \%)$ \\
\hline
\end{tabular}

Table 3 shows the CT scan findings of head which was done to confirm the diagnosis of stroke.

Table 3: CT scan findings

\begin{tabular}{|c|c|c|}
\hline $\begin{array}{c}\text { Types } \\
\text { of stroke }\end{array}$ & Number & $\begin{array}{c}\text { Mean Age } \\
\text { (years) } \pm \text { SD }\end{array}$ \\
\hline Ischemia & 20 & $63.85 \pm 11.70$ \\
\hline Hemorrhage & 30 & $64.60 \pm 12.05$ \\
\hline
\end{tabular}

The CT scan shows the types of stroke whether it is ischemic or hemorrhagic. In the 
study it was found that $20(40 \%)$ were ischaemic and $30(60 \%)$ were hemorrhagic.

The study shows that out of 28 male patients, $18(64.28 \%)$ were hemorrhagic stroke and rests were ischaemic stroke. Similarly, among 22 females, 12 (54.54\%) were hemorrhagic and 10 (45.45\%) were ischaemic (figure 5).

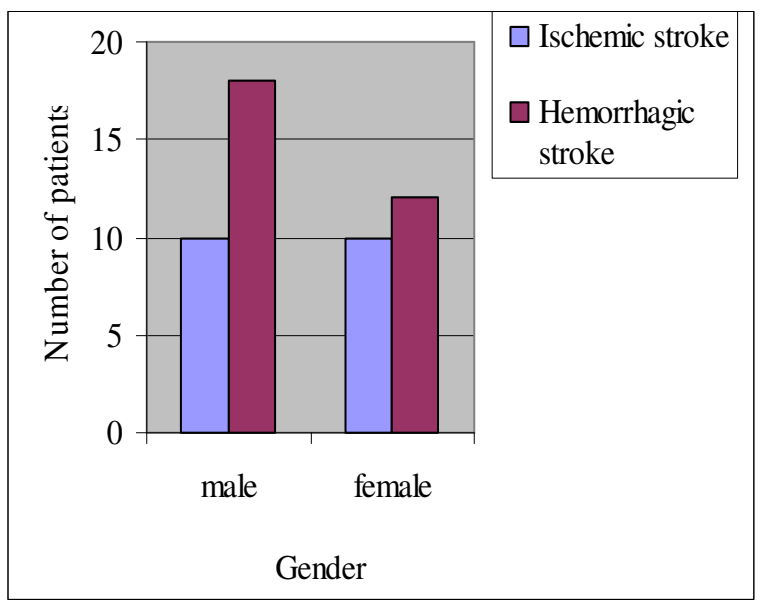

Figure 5: Gender and types of stroke

The relation of smoking habits and types of stroke is presented in figure 6 and 7.

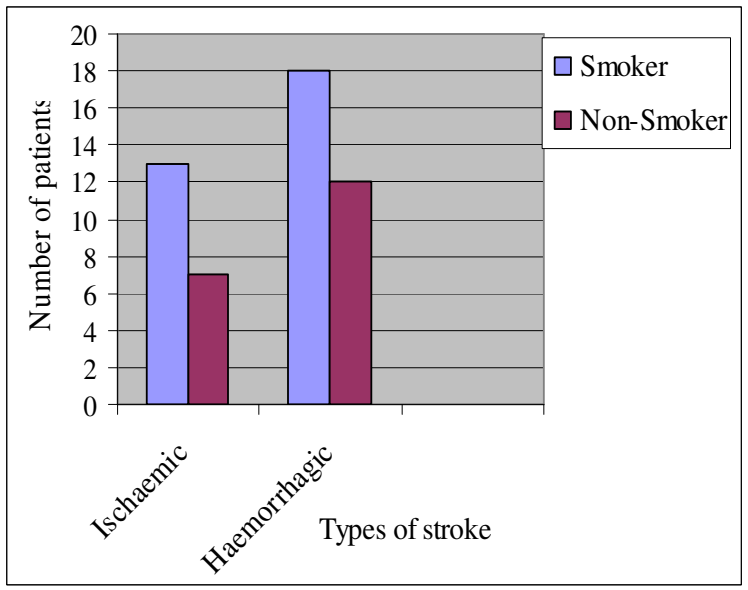

Figure 6: Smoking and types of stroke

Smoking was most prevalent in patients with ischemic stroke. The risk factors were present in $13(65 \%)$ patients whereas $7(35 \%)$ were non-smokers among $20(40 \%)$ ischemic patients. $18(60 \%)$ patients had smoking as a risk factor among 30 (60\%) hemorrhagic stroke patients.

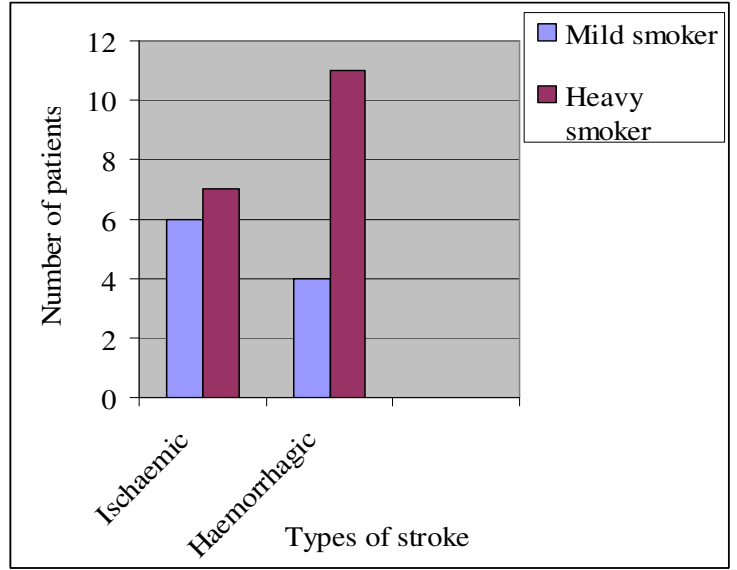

Figure 7: Level of smoking and types of stroke

As per the level of smoking, among 28(56\%) smokers, $11(73.33 \%)$ were heavy smokers and $4(26.66 \%)$ were mild smokers in hemorrhagic stroke patients and in case of ischaemic stroke $7(53.84 \%)$ were heavy and 6(46.15\%) were mild smokers.

The common complaints of the stroke patients in the study population are given below in the table 4 .

Table 4: Stroke - Presenting complaints

\begin{tabular}{|l|c|c|}
\hline Complaints & $\begin{array}{c}\text { Number of } \\
\text { cases }\end{array}$ & $\begin{array}{c}\text { Percentage } \\
\text { (\%) }\end{array}$ \\
\hline Weakness of limbs & 41 & 82 \\
\hline Drowsy & 31 & 62 \\
\hline Slurring of speech & 22 & 44 \\
\hline Headache & 12 & 24 \\
\hline $\begin{array}{l}\text { Deviation of angle of } \\
\text { mouth }\end{array}$ & 11 & 22 \\
\hline Others* & 5 & 10 \\
\hline *Vomiting, fever, seizure, tingling sensation of limbs, coma \\
\hline \multicolumn{2}{|l}{} \\
\hline
\end{tabular}

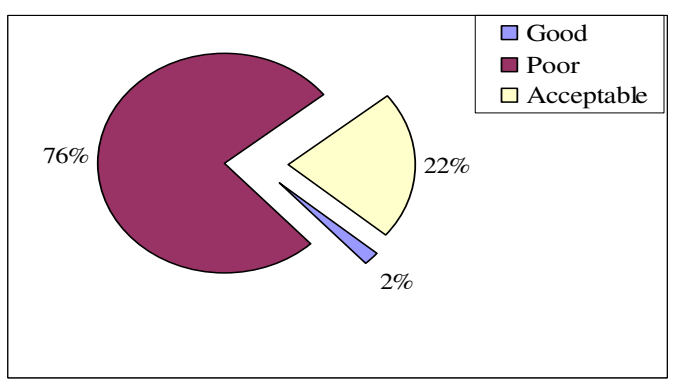

Figure 8: Patient knowledge about the stroke 
Figure 8 shows the level of knowledge of patients about stroke regarding causes, risk factors and complications. Patient knowledge about the disease was poor in most of the patients $(76 \%)$.

Table 5 shows the prescribing pattern or medication used by the patients and table 6 shows different kinds of problems related to medication with their frequencies and percentage are shown below in the table 6 .

Table 5: Prescribing pattern of antihypertensive drugs

\begin{tabular}{|l|c|c|}
\hline $\begin{array}{l}\text { Anti-hypertensive } \\
\text { Drugs }\end{array}$ & Number & $\begin{array}{c}\text { Percentage } \\
\text { (\%) }\end{array}$ \\
\hline Diuretics & 1 & 2.32 \\
\hline ACE inhibitors & 3 & 6.97 \\
\hline $\begin{array}{l}\text { Calcium channel } \\
\text { blockers }\end{array}$ & 19 & 44.18 \\
\hline $\begin{array}{l}\text { ACE inhibitors and } \\
\text { Diuretics }\end{array}$ & 3 & 6.97 \\
\hline $\begin{array}{l}\text { Calcium channel } \\
\text { blockers and Diuretics }\end{array}$ & 8 & 18.60 \\
\hline $\begin{array}{l}\text { Calcium channel } \\
\text { blockers and ACE } \\
\text { inhibitors } \\
\text { Total }\end{array}$ & 9 & 20.93 \\
\hline
\end{tabular}

Figure 9 shows the percentage of patients improvement in health conditions in followup cases. It was observed that 40 patients $(80 \%)$ were improved and 10 patients (20\%) were not improved.

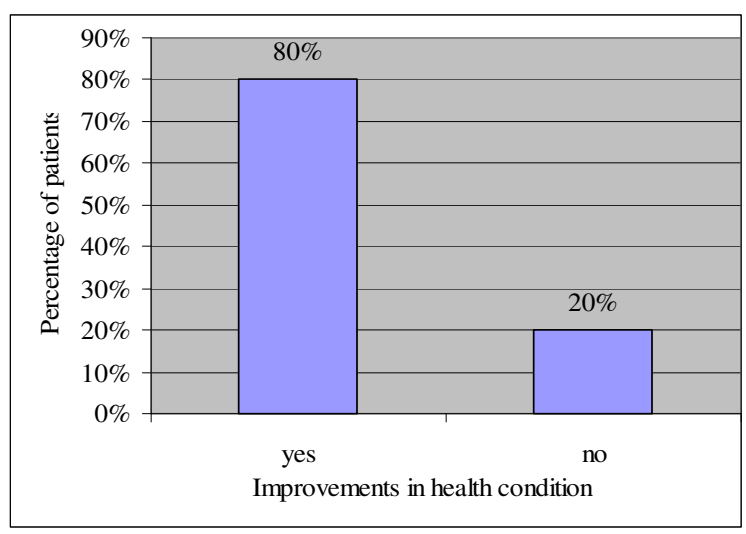

Figure 9: Percentage of patients' improvement in health condition

\section{DISCUSSION}

The study showed that percentage of stroke patients of the age group greater than 60 years was $70 \%$. Twenty one male (42\%) and 14 (28\%) female stroke patients were above or equal the age of 60 years which supports the fact that males are more prone to stroke which is similar to the findings of previous studies done in Nepal $[5,6]$. Stroke incidence rates are 1.25 times greater in men than women [7] but women tend to live longer than men, more women than men die of stroke each year.

Among different risk factors hypertension is the commonest risk factor in this study. Similar results was shown by other previous studies done by Bhatt et al. [5], Naik et al. [8] and Devkota et al. [6]. The study showed that

Table 6: Percentage of patients with kinds of problems related to medications

\begin{tabular}{llc}
\hline Kinds of problems & Number & Percentage (\%) \\
\hline Forgetfulness & 6 & 18.18 \\
Inconvenience in carrying drugs & 4 & 12.12 \\
Incompliance due to multiple dosages & 17 & 51.52 \\
Incompliance due to side effects & 6 & 18.18 \\
Total & $\mathbf{3 3}$ & $\mathbf{1 0 0}$ \\
\hline
\end{tabular}


$86 \%$ of stroke patients were hypertensive. Among this $38 \%$ of stroke patients were only known about their hypertension. $48 \%$ of patients did not know about their hypertension before but were present during their examination. As the age increases different diseases attack the body.

Primary hypertension is one of the common diseases found in Nepalese population. But due to lack of education, people are unaware of this disease. Similarly either because of lack of knowledge or due to financial problems, people does not visit the hospital. Uncontrolled hypertension causes the stroke. Chronic hypertension weakens the small deep penetrating arteries of the brain producing microaneurism which gets rupture giving rise to intracranial hemorrhage. During the study, patient knowledge about stroke regarding causes, risk factors and complications were also studied. Different open questions were asked to know the knowledge about stroke and were categorized into different groups as good, poor and acceptable (figure 8). Only 1 patient (2\%) had the good knowledge who had the family history of stroke. 38 patients (76\%) had the poor knowledge and $11(22 \%)$ had acceptable knowledge. Patient knowledge about the disease was poor in most of the patients (76\%). The study conducted by Bhatt et al. shows the similar results comprising 9.83\% good, $44.26 \%$ acceptable and $45.90 \%$ poor knowledge of the disease [5]. Majority of the patients enrolled in the study belonged to the rural area, which suggests that stroke is more prevalent in them. Majority of them were from poor socioeconomic status and were illiterate. They had little information about the disease and its contributing factors.

The study showed that the level of consumption of alcohol was the second and smoking was the third modifiable risk factor in this study. Alcohol consumption was seen in a large proportion of stroke patients which proves that it is one of the common modifiable risk factors and is similar to the study done by Devkota et al. [51]. Though the quantity of alcohol was classified into mild and heavy, it was difficult in quantifying the amount of alcohol consumed. Alcohol consumption might contribute to stroke in several ways like induction of cardiac arrhythmia which predispose to cerebral embolism, induction of hypertension, activation of clotting cascade and platelet aggregation. A meta analysis has shown that alcohol consumption of less than $12 \mathrm{~g} /$ day is significantly associated with a decreased relative risk of total stroke as it tends to raise level of HDL 'good cholesterol' but consumption of more than $60 \mathrm{~g} /$ day is significantly associated with an increased relative risk of total stroke [10].

The study showed that $28(56 \%)$ of patients diagnosed of stroke were smokers, which was the third commonest modifiable risk factors in the population studied. Further, in this study smokers were again classified into mild smoker (less than 9 cigarettes/ day) and heavy smoker (greater than 9 cigarettes / day). The patients who were found to smoke more than 9 cigarettes / day since more than 5 years were classified as heavy smoker while those who smoke less than 9 cigarettes/day since 5 years were classified as mild smoker. Majority of the smoking patients 18 (64.28\%) with stroke were found to be heavy smoker, whereas, 10 (35.71\%) were mild smoker. Hence, the study showed that heavy smokers were more susceptible towards stroke. Previous studies show similar results about the smoking as modifiable risk factors, Bhatt et al. 57\% [5], Naik et al. 41\% [8] and Devkota et al. 58\% [6]. Several observational studies $[5,9]$ have shown a dose-response 
relationship between cigarette smoking and stroke. Cigarette smokes contain nicotine and carbon monoxide. These ingredients lower oxygen level on blood. With lower oxygen level in the blood and damaged vessels wall due to smoke, clots may form in blood and blood pressure increases, as a result stroke can occur. Smoking increase blood pressure by sympathetic stimulation and smoking accelerates the process of atherosclerosis.

The other modifiable risk factors of stroke with their prevalence besides hypertension, consumption of alcohol and smoking, are presented in table 2. All of these risk factors are associated with stroke. This corresponds to the result of the study conducted by Bhatt et al. comprising of $34 \%$ diabetes, $21 \%$ hypercholesterolemia, $8.19 \%$ cardiac disease [5].

A person with diabetes is at the higher risk than others for ischaemic stroke [10]. Persistent elevated blood glucose level contribute to atherogenesis and increase thrombosis due to platelet hyperaggegability, reduce fibrinolytic activity, elevated fibrinogen and factors vii, viii. American diabetes association says that people with HBA1C level above $7 \%$ are nearly 3 times as likely to have stroke as people with HBA1C level below 5\% [5].

People with high blood cholesterol have an increased risk for stroke. Also it appears that low HDL 'good' cholesterol is a risk factor for stroke in men. Observational studies suggest that higher total and lower density lipoprotein cholesterol level are associated with the greater risk of ischemic stroke, while lower cholesterol levels are associated with a greater risk of hemorrhagic stroke [11].

Stress might trigger a cerebrovascular event directly or could be associated with levels of blood pressure or an unfavorable lifestyle.
There is a link to stress in those cases where the stroke is caused by atherosclerosis or to the blood clots that have developed locally in the smaller vessels of the brain [12].

Drug addiction is often a chronic relapsing disorder associated with a number of societal and health-related problems. Drugs that are abused, including cocaine, amphetamines and heroin, have been associated with an increased risk of stroke. Strokes caused by drug abuse are often seen in younger populations [13].

Diets high in saturated fat, trans fat and cholesterol can raise blood cholesterol level. Diets high in sodium (salt) can contribute to increase blood pressure. Diets with excess calories can contribute to obesity. Also, a diet containing five or more servings of fruits and vegetables per day may reduce the risk of stroke [14].

Table 3 shows the CT scan findings of head which was done to confirm the diagnosis of stroke. The CT scan shows the types of stroke whether it is ischemic or hemorrhagic. In the study it was found that $20(40 \%)$ were ischaemic and $30(60 \%)$ were hemorrhagic. The study showed that in developing countries like Nepal, India, China, hemorrhagic stroke constitutes a large percentage of stroke partly because of poorly controlled hypertension, the outcome of which is poor $[14,15]$.

The study shows that out of 28 male patients, 18 (64.28\%) were with hemorrhagic stroke and rests were having ischaemic stroke. Similarly, among 22 females, 12 (54.54\%) were hemorrhagic and 10 (45.45\%) were ischaemic. Thus, in the study it was found that in both gender the haemorrhagic was more common than ischaemic stroke. Similar results were observed in the study done 
previously in Hongkong Chinese by Haung et al. [16].

Smoking was most prevalent in patients with ischemic stroke. The risk factors were present in $13(65 \%)$ patients whereas $7(35 \%)$ were non-smokers among 20 (40\%) ischemic patients. $18(60 \%)$ patients had smoking as a risk factor among 30 (60\%) hemorrhagic stroke patients. This result also corresponds to the result of the study conducted by Devkota et al. in Nepal medical college, $44.3 \%$ patients with ischemic stroke had smoking as risk factor [6].

As per the level of smoking, among 28(56\%) smokers, $11(73.33 \%)$ were heavy smokers and $4(26.66 \%)$ were mild smokers in hemorrhagic stroke patients and in case of ischaemic stroke $7(53.84 \%)$ were heavy smokers and $6(46.15 \%)$ were mild smokers.

This study shows that the commonest complaints during presenting in the hospital were weakness of limbs (82\%), drowsy (62\%), slurring of speech (44\%) followed by others. Similar findings were observed in the study done by Devkota et al. [6] comprising, weakness of limbs (90.3\%), slurring of speech (33.3\%) and drowsy (29.2\%).

Patient Compliance in stroke: For the study of compliance, the follow up of patients were done. Among 50 patients, 37 patients (74\%) were taking drugs and 13 patients (26\%) were not taking drugs as per the prescription. When the patients were asked for the reason of not taking the drugs, it was found that patients were having problems with medication. The patients who were taking drugs as per the prescription were also having the problems with the medication. Among 50 patients, 33 patients (66\%) were having problems with medication and 17 patients (34\%) were not having problems with medication. The non compliance to the drugs was due to multiple dosages (51.52\%), side effects (18.18\%) and forgetfulness (18.18\%).

\section{CONCLUSION}

This study performed in the UCMS teaching hospital, produced important findings which has supported the reported risk factors of stroke in other similar studies. The conclusion of the study can be summarized as:

The present study showed that Hemorrhagic stroke $(60 \%)$ was more than the ischemic stroke $(40 \%)$ and age was the common non modifiable risk factor. The commonmodifiable risk factors were hypertension, alcohol consumption and smoking. The common presenting complaints were weakness of limbs, drowsiness, slurring of speech, headache, and deviation of angle of mouth followed by others symptoms. Calcium channel blocker and combination of it with Diuretic and ACE inhibitors were the commonly prescribed drugs for lowering blood pressure. Other drugs used were antiplatelets, statins etc. Prescribed drugs therapy and lifestyle modification improved the health condition of patients. The non compliance to the drugs was due to multiple dosages, side effects and forgetfulness.

Finding of this study will be helpful for the practitioners as well as researcher in the future. Practitioners can make people aware on the risk factors and preventive measures of the stroke. Researchers will be helped by knowing the commonest risk factors of stroke and its management pattern.

\section{ACKNOWLEDGEMENT}

We would like to thank Department of medicine UCMS and all the participants of the 
study for their cooperation and help. We would like to express our special thanks to Visiting Professor (at Little Angles College) Kshitiz Upadhyay-Dhungel for his support in preparing manuscript.

\section{REFERENCES}

1. Aleen CM, Leuck CJ, cerebrovascular disease In: Haslett c, Chilvers ER, Hunter JAA, Boon NA. Daavidson's Principles and practice of medicine. $18^{\text {th }}$ edition.Edinburgh: Churchill Livingstone, 1999;974983.

2. Easton JD, Hauser SL, Martin JB. Cerebrovascular disease. In: Fausi As, Braunwald E, Isselbacher KJ, Wilson JD, Martin JB, Kasper DL, Hauser Sl, Longo DL Harrison's Principle of internal medicine $15^{\text {th }}$ edition. Vol 2. Newyork: McGraw-Hill, Inc., 1998;2325-48.

3. Murray CJL, Lpez AD. Global pattern of cause of death and burden of disease in 1990, with projection to 2020-investing in health research and development: report of the ad hoc committee on health research relating to future interventionoptions.Geneva:WHO,1996.

4. Warlow CP, Dennis MS, Van Gijn J et Al. Reducing the burden of stroke and improving the public health. In: Warlow CP, Dennis MS, Van Gijn J et Al, eds. Stroke A practical guide to management. Oxford:Blackwell Science Ltd. 1996:632-49.

5. Bhatt V.R, Parajuli N, Mainali N.R, ;Risk factors of stroke; Journal of Institute of Medicine, December, 2008; 30:3; 37-41.

6. Devkota KC, Thapamagar SB and Malla S : Retrospective analysis of stork and its risk factors at Nepal Medical College Teaching Hospital: Nepal Medical college Journal(2006)Dec;8(4):269-75.

7. Zhang Y, Galloway JM,Welty TK; Incidence and Risk factors for stroke in American Indians( the strong heart study);circulation;2008;118:1577-1584.

8. Naik M, Rauniyar RK, Sharma UK Clinicoradiological profile of stroke in eastern Nepal: Kathmandu University Medical Journal (2006), Vol. 4, No. 2, Issue 14, 161-166

9. Shinton R, Beevers G. Meta-analysis of relation between cigarette smoking and stroke. BMJ. 1989;298:789-794.

10. Burchfiel CM, Curb JD, Rodriguez BL, Abbott RD, Chiu D, Yano K. Glucose intolerance and 22-year stroke incidence: the Honolulu Heart Program. Stroke. 1994; 25:951-957.

11. Gill JS, Shipley MJ, Tsementzis SA et al. Alcohol consumption - a risk factor for hemorrhagic and non-hemorrhagic stroke. Amer J Med 1991; 90: 48997.

12. Ohira T, Shahar E, Chambless LE: Risk Factors for Ischemic Stroke Subtypes: The Atherosclerosis Risk in Communities Study Stroke 2006; 37;2493-2498.

13. Kelly MA, Gorelick PB, Mirza D. The role of drugs in the etiology of stroke. Clin Neuropharmacol. 1992;15:249-275.

14. Eastern Stroke and Coronary Heart Disease Collaborative Research Group. Blood pressure, cholesterol, and stroke in eastern Asia. Lancet 1998;352:1801-7.

15. Asian Actual Stroke Advisor Panel (AASAP). Stroke epidemiological data of nine Asian countries. J Medicine Association Thai 2000;83:1-7.

16. Haung CY, Chan FI, Yu YI et al. Cerebrovascular disease in Hong Kong Chinese. Stroke 1990; 21:230. 